\title{
Al2024-CNTs Composites by Mechanical Alloying
}

\author{
R. Pérez-Bustamante,* F. Pérez-Bustamante,* W. Antúnez-Flores, * J. M. Herrera-Ramírez, * \\ I. Estrada-Guel,* P. Amezaga-Madrid,* M. Miki-Yoshida,* and R. Martínez-Sánchez * \\ * Centro de Investigación en Materiales Avanzados (CIMAV), Laboratorio Nacional de \\ Nanotecnología, Miguel de Cervantes No.120, C.P. 31109, Chihuahua, Chih., México.
}

Carbon nanotubes (CNTs) were dispersed by mechanical milling into a 2024 aluminum alloy $\left(\mathrm{Al}_{2024}\right)$ in order to produce composites and study the influence of CNTs content over the mechanical and microstructural behavior of them. The time of milling was set to $5 \mathrm{~h}$ [1] and the addition of CNTs was of 0.0 to $5.0 \mathrm{wt}$. \%. Powders obtained from milling process were cold compacted and then sintered under argon atmosphere by $2 \mathrm{~h}$ with $5^{\circ} \mathrm{C} / \mathrm{min}$ for heating and cooling rates. The microstructural analysis was carried out by scanning electron microscopy (SEM), transmission electron microscopy (TEM) and X-ray diffraction (XRD). In the other hand, their mechanical performance was evaluated by microhardness Vickers. Microhardness values from several aluminum commercial alloys reported in literature were compared with these experimental results.

CNTs used as material reinforced are shown in Figs. 1(a,b). Diameters of $\sim 80 \mathrm{~nm}$ and lengths of $\sim 0.8 \mathrm{~mm}$ were observed. Fig. 1c displays the microstructure after sintering process. It can be observed a well dispersion $\mathrm{Al}_{2} \mathrm{Cu}$ phase produced by low cooling rate in sintering treatment. Figs. 1 (d,e) present bright field TEM micrographs from the composites with 1.0 and $5.0 \mathrm{wt} . \%$, respectively. CNTs are observed in Fig. If from the composite with $1.0 \mathrm{wt} \% \%$ of nanotubes. A second phase characterized as $\mathrm{Al}_{4} \mathrm{C}_{3}$ is shown in Fig. 1g. Fig. 2a shows the results from XRD of the $\mathrm{Al}_{2024}-\mathrm{CNTs}$ composites as a function of the CNTs content. An increase in the peaks intensity attained to the aluminum carbides (Fig. 1e, marked with circles, and $1 \mathrm{~g}$ ) is observed as function of the CNTs content. However no variation was observed for the $\mathrm{Al}_{2} \mathrm{Cu}$ intensity peaks. The presence of CNTs after milling process and sintering heat treatment was verified by TEM as is shown in Fig. $1 \mathrm{~g}$.

The mechanical characterization of the composites indicates that a rapid increament in mechanical properties is observed as a function of the addition of the CNTs (Fig. 2b). The maximum Vickers hardness value (219.74 VHN) observed in this work was reached by the sample with $5.0 \mathrm{wt} . \%$ of CNTs, this value represents $\sim 346 \%$ (170.56 hardness units) over the pure Al hardness value. The composite with $3.0 \%$ of CNTs gives a similar value to that reported by the $\mathrm{Al}_{2024}$-T6 commercial alloy [2]. Values reported in this work are comparable and in some case higher than those reported for $\mathrm{Al}_{2024}$ after particular temper, this open the possibility that mechanical properties reported in this work can be enhanced by a T6 or any other commercial temper.

\section{References}

[1] R. Pérez-Bustamante, et al., J. of Alloys and Comps. 450 (2008) 323-326.

[2] www.matweb.com, online materials information resource.

[3] Thanks to E. Torres-Moye and C. Ornelas-Gutiérrez por their valuable technical assistance. 


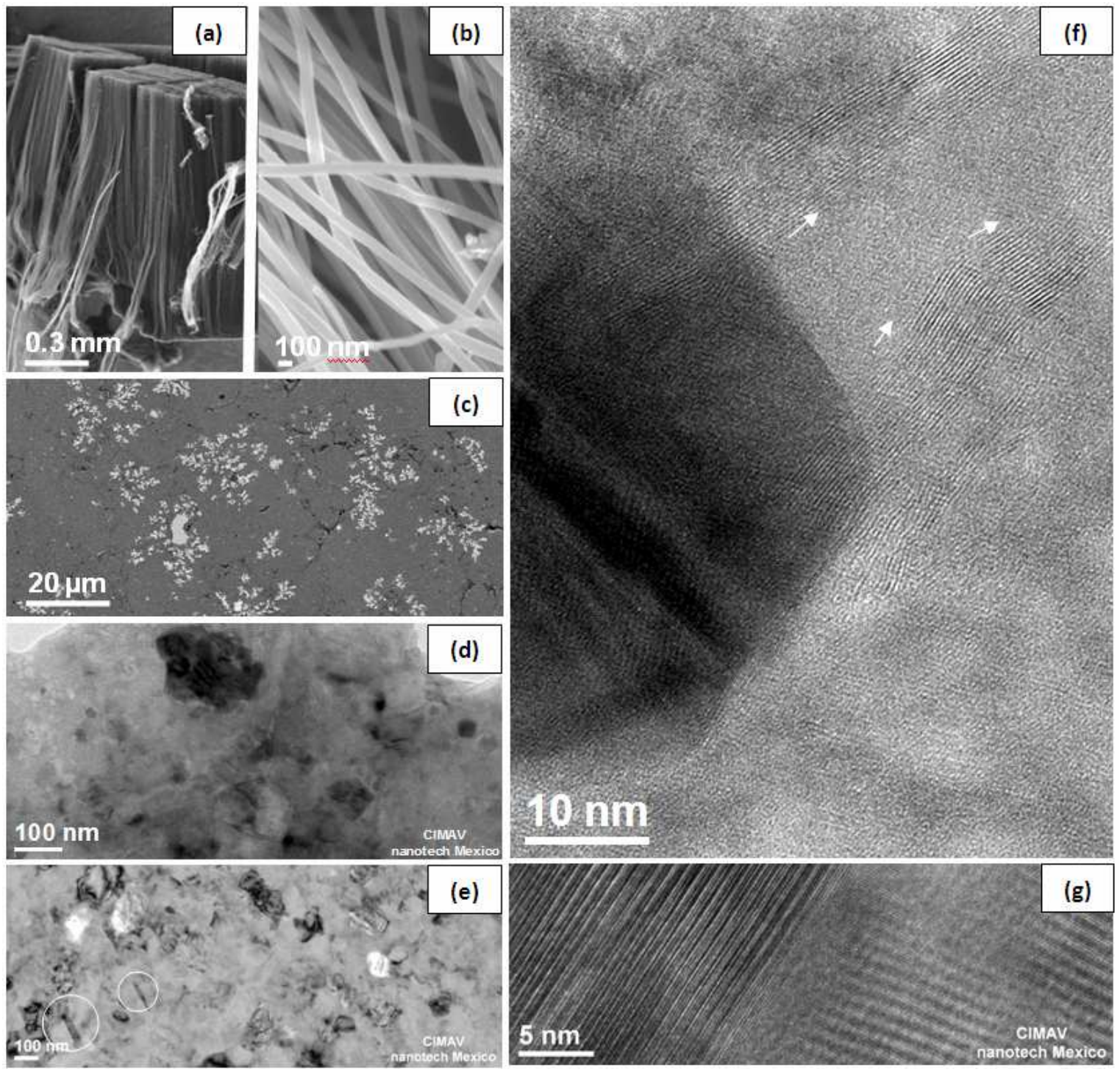

FIG. 1. (a,b) CNTS used in the production of $\mathrm{Al}_{2024}$-CNTs composites. (c) Microstructure of the composite with $5.0 \mathrm{wt}$ \% of CNTs. (d,e) TEM micrographs of the composites with 1.0 and $5.0 \mathrm{wt}$. $\%$ of CNTs. (f) CNTs into the composite with $1.0 \%$ of CNT and (g) $\mathrm{Al}_{4} \mathrm{C}_{3}$ observed in Fig. $1 \mathrm{e}$.
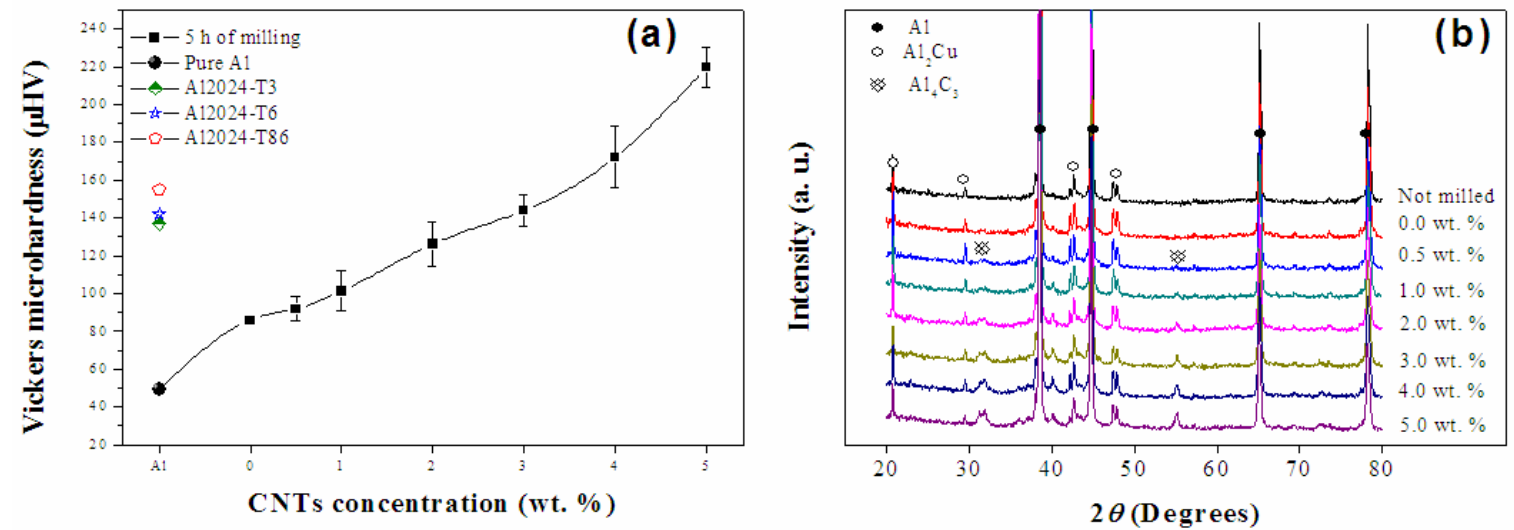

FIG. 2. (a) Results from microhardness test. (b) XRD patterns from the AA2024-CNTs composites. 